\title{
Association between dietary protein intake and type 2 diabetes varies by dietary pattern
}

Qiuyi Ke ${ }^{1 \dagger}$, Chaogang Chen ${ }^{2 \dagger}$, Fengyi He${ }^{2}$, Yongxin Ye ${ }^{1}$, Xinxiu Bai ${ }^{1}, \mathrm{Li} \mathrm{Cai}^{3^{*} \neq}$ and Min Xia ${ }^{1 * \neq}$

\begin{abstract}
Background: Epidemiological studies have demonstrated that high total protein intake was related to type 2 diabetes mellitus (T2DM) risks. However, few studies considered the impact of dietary pattern.

Objective: We examined the associations between protein intake and T2DM in different dietary patterns.

Methods: We used the demographic and dietary information of adults aged 18-75 years from the China Health and Nutrition Survey (2009), consisting of 4113 women and 4580 men. Dietary data was collected by using 24-h recalls combined with a food inventory for 3 consecutive days. Cluster analysis was used to classify subjects into groups, as determined by major sources of protein. Logistic regression models were used to calculate odds ratios (OR) and 95\% confidence interval $(95 \% \mathrm{Cl})$ of T2DM according to the energy-adjusted protein intake.

Results: All participants were divided into three patterns according to the dietary source of protein (legumes and seafood, red meat, refined grains). Overall, plant protein intake was significantly and inversely associated with T2DM. In the subgroup analysis by dietary patterns, extreme quartile of plant protein intake was also inversely related to T2DM in the "legumes and seafood" group $[\mathrm{OR}=0.58,95 \% \mathrm{Cl}(0.33-0.96)]$. Total protein intake and animal protein intake were positively related to T2DM in the "red meat" group [OR: 3.12 (1.65-5.91) and 3.48 (1.87-6.60), respectively]. However, the association of animal protein intake was reversed in the "refined grains" group [OR $=0.55,95 \% \mathrm{Cl} 0.32-0.89]$.
\end{abstract}

Conclusions: The association between protein intake and T2DM varies by dietary pattern. Dietary pattern may be considered into the recommendation of protein intake for diabetes prevention.

Keywords: Dietary, Protein, Dietary pattern, Type 2 diabetes mellitus

\section{Background}

Type 2 diabetes mellitus (T2DM) becomes a major cause of morbidity and mortality globally and contribute considerably to health care costs [1]. The prevalence of T2DM in China has increased substantially from $0.9 \%$ in

\footnotetext{
*Correspondence: caili5@mail.sysu.edu.cn; xiamin@mail.sysu.edu.cn ${ }^{\dagger}$ Qiuyi Ke and Chaogang Chen contributed equally to this work and should be considered co-first authors

"Li Cai and Min Xia contributed equally to this work and should be considered co- correspondence authors

${ }^{1}$ Department of Nutrition, School of Public Health, Sun Yat-sen University (Northern Campus), Guangzhou 510080, Guangdong Province,

People's Republic of China

${ }^{3}$ Department of Maternal and Child Health, School of Public Health, Sun

Yat-sen University (Northern Campus), Guangzhou 510080, Guangdong

Province, People's Republic of China

Full list of author information is available at the end of the article
}

1980 to $11.6 \%$ in 2011 due to the great changes of lifestyles and dietary habits [2]. Therefore, the identification of modifiable risk factors that may contribute to the prevention of T2DM is of essential importance.

Dietary proteins and amino acids are important modulators of glucose homeostasis by promoting insulin resistance and increasing gluconeogenesis [3]. Although high-protein diet has shown beneficial effects on glucose homeostasis in short-term trials [4], emerging evidence suggest that protein actions on T2DM incidence may vary by the amino acid types and food sources. Previous findings from a few long-term epidemiologic studies evaluating food sources of protein reported the conflicting associations of animal and plant protein with risk of T2DM. High total and animal protein intake were 
associated with a modest elevated risk of T2DM in a large cohort of European adults, but plant protein intake was not associated with T2DM [5, 6]. Higher intake of animal protein such as red and processed meat has been positively associated with risk of T2DM [7], while intake of plant-based sources of protein [8], such as nuts [9], legumes and soy food [10], has been associated with a significantly lower risk of T2DM.

Thus, it is still unclear why the association between different kinds of high-protein food and the risk of T2DM is inconsistent. Furthermore, whether other components in protein-rich foods (e.g., sodium, nitrates, and nitrites in processed red meat), in addition to protein per se, may have a critical health effect and account for observed associations.

Patterns of dietary intake reflect an individual's habitual consumption and would not change for a long time. In practice, each nutrient or food is part of a larger pattern consisting of many nutrients and foods, and thus, characterization of multiple, concurrent dietary exposures have particular relevance to health. It can evaluate individual protein intake in a whole-diet perspective, and make a more practical recommendation for public as dietary guidelines focus on dietary patterns. To date, no studies have considered the association between protein intake and T2DM in different dietary patterns. Therefore, in this study, we extracted and analyzed data from the China Health and Nutrition Survey to determine the association between dietary protein intake and T2DM in different dietary patterns.

\section{Methods}

\section{Study population}

The China Health and Nutrition Survey (CHNS), an ongoing large-scale longitudinal survey initiated in 1989, creates a multilevel method of data collection from all community-dwelling participants and their communities to understand how the wide-ranging set of socioeconomic changes in China affect the health and nutritional status of its population. A multistage random-cluster process was utilized to draw the sample geographically covering 12 provinces in China, which were chosen to generally represent divergence in public resources, health indicators and economic development of all provinces in the country. Eight additional rounds were completed in 1991, 1993, 1997, 2000, 2004, 2006, 2009, and 2011. Details of procedures are described elsewhere [11, 12].

Briefly, to investigate associations between dietary protein and T2DM risk, the cross-sectional data were extracted from the 2009 wave of CHNS, during which fasting blood sample and measurements were collected for the first time. From a total of 9323 eligible adults aged
18 years or older who completed dietary data and biomarker assessment, we excluded 247 participants diagnosed with pregnancy, myocardial infarction or apoplexy, 302 participants with abnormal total energy intake (daily energy intake $\geq 4000$ or $\leq 800 \mathrm{kcal} /$ day), and $81 \mathrm{partici}$ pants with a weight loss diet. Thus, the final analysis consisted of 4113 women and 4580 men.

\section{Assessment of type 2 diabetes}

Blood samples were collected in the morning after overnight fasting via venipuncture by experienced staff, and were frozen at $-86{ }^{\circ} \mathrm{C}$ for later laboratory analysis. Plasma glucose and hemoglobin A1c (HbA1c) were measured with standard procedures and strict quality control [11]. T2DM was confirmed according to the diagnostic criterion of HbA1c at or above $6.5 \%$. In contrast to the current diagnostic tests based on point-in-time measures of fasting and postload blood glucose, HbA1c better reflects long-term glycemic exposure and has been demonstrated to be reliable for T2DM diagnosis among Chinese subjects [13].

\section{Assessment of dietary protein and other nutrients}

Before the survey, all field staff, who professionally engaged in nutrition work, were well trained to be acquainted with the containers and food information of region surveyed. 3 consecutive 24 -h recalls which were randomly allocated in a week combined with a food inventory over the same three periods to adjust for cooking oil and condiment consumption, were utilized to collect the dietary information. More details about the collection of dietary information can be found elsewhere [14]. The 2002 and 2004 Food Composition Table [15, 16] (Chinese Center For Disease Control And Prevention, Beijing, China) was used to convert food consumption into subjects' daily intake of nutrients (e.g., protein intake, Energy, fiber, cholesterol). Individual daily intake of each nutrient was adjusted for total energy intake by using the regression residual method [17]. Daily protein intake contributed from each food item was calculated in g/day and grouped into 12 pre-defined food groups (each food group contributing more than $0.5 \%$ total daily protein) which were based on similar protein source, nutrient composition, mainly according to the latest 2016 Chinese Dietary Guidelines [18]. The groups included red meat (e.g., pork, beef, and lamb), poultry (e.g., chicken, duck, and goose), dairy (e.g., cow's milk, yogurt, and milk powder), eggs, seafood (including freshwater fish, e.g., yellow croaker, carp, and shrimp), refined grains (e.g., rice, wheaten food), coarse grains (e.g., oats, maize), tubers, legumes and its products, nuts and seeds, vegetables, and fruits. Then each percentage of total protein intake [protein from specific food group (g/day)/ 
total protein intake (g/day) $\times 100$ ] was calculated for subsequent cluster analyses.

\section{Assessment of covariates}

Unified trained interviewers administered a detailed questionnaire to collect information including sociodemographic characteristics (e.g., age, gender, education level and annual income), lifestyle factors (e.g., physical activity, smoking status, consumption of tea, coffee and alcohol).

Height (nearest $0.1 \mathrm{~cm}$ ) and weight (nearest $0.1 \mathrm{~kg}$ ) were measured in a research clinic affiliated with the academic medical center by trained assessment staff using consolidated tools. Body mass index (BMI) $\left(\mathrm{kg} / \mathrm{m}^{2}\right)$ was calculated as weight $(\mathrm{kg})$ divided by height squared $\left(\mathrm{m}^{2}\right)$. Physical activities level (PAL) was administered by addressing the question "PAL involved in work", whose answer divided into very light (working in a sitting position, office worker, watch repairer, etc.), light (working in standing position, salesperson, teacher, etc.), moderate (student, metal worker, etc.), heavy (farmer, steel worker, etc.) and very heavy (loader, miner, etc.). Furthermore, PAL was quantized into multiples of basal metabolism rate (BMR) according to the basis of Chinese Dietary Reference Intakes [19]: $1.3 \times$ BMR for very light in both sexes, 1.6 and $1.5 \times$ BMR for light, 1.7 and $1.6 \times$ BMR for moderate, 2.1 and $1.9 \times \mathrm{BMR}$ for heavy, 2.4 and $2.2 \times$ BMR for very heavy in males and females, respectively. Education level was categorized into low (primary school and lower), middle (middle school and technical or vocational school) and high (college, university and higher). Smoking status was divided into yes (more than once a month or former) and no (never). Consumption of tea, alcohol and coffee were coded as yes (more than once a month) or no (no more than once a month). Annual income was divided into four groups $(<9000$; 9000-15,000; > 15,000-25,000; and > 25,000 RMB).

\section{Statistical analysis}

Characteristics of populations were described by proportions for categorical variables, means and standard deviation for normal distribution, and medians and interquartile ranges for skewed distribution of continuous variables. Total, animal, and plant protein intake, with adjustment for total energy intake by the regression residual method [17], were categorized into quartiles respectively.

Dietary patterns were derived by protein-rich food groups, using fast cluster models in cluster package. Firstly, the percentage of total daily protein that was contributed from each food was calculated for each individual. Foods containing protein were grouped into 12 predefined food groups on the basis of nutrient-composition similarities, protein type, or source according to mainly according to the latest 2016 Chinese Dietary Guidelines. Secondly, dietary patterns were derived by protein-rich food group, using fast cluster models in cluster package. The technique applied K-means method of cluster analysis to categorized subjects into mutually exclusive groups by Euclidean distance between each person and each cluster center in an iterative process. We excluded participants whose protein contributions from food groups were 5 standard deviations away from the mean protein contributions and verified each food groups contributing more than $0.5 \%$ total daily protein because cluster analysis is sensitive to outliers. Thirdly, we ran predetermined numbers of clusters (2-6 times) to determine the most meaningful interpretation according to dietary feature of Chinese population. The 3-cluster set was chosen because it presented the most meaningfully separated clusters, also including a high $\mathrm{F}$ ratio (mean square between clusters/mean-squared error), and each clusters distributed participants well between all clusters (each cluster contained more than 100 subjects). Naming of clusters was determined by the value which represent the highest consumption of one or two food groups compared with other clusters. The methods were previously performed in other studies [20,21], and discussion (such as attention, background) of cluster methods have been described elsewhere [22, 23].

Logistic regression models were used to calculate crude, adjusted odd ratios (ORs) and 95\% confidence interval (CI) for the associations of quartiles of energyadjusted protein intake, animal protein intake, and plant protein intake with T2DM. P for trend was conducted by taken the median of each energy-adjusted protein intake quartile as continuous variables in the logistic regression models. In multivariate models, model was adjusted for age and sex firstly. In the second model, model was further adjusted for the covariates, such as PAL, smoking status, alcohol consumption, tea consumption, coffee consumption, annual income and education (low, middle, or high). In the third model, the nutritional factors was added to the model, included total energy, carbohydrate to energy ratio from refined grains or tubers, from the other plant sources and energy-adjusted intake of saturated fat, monounsaturated fat, polyunsaturated fat, fiber, cholesterol. In the last model, BMI was additionally considered. Subgroup analysis by dietary protein food patterns was conducted to explore the relation between energy-adjusted protein intake with prevalence of T2DM 
in mutually exclusive subjects with different dietary preferences. Data was analyzed by $\mathrm{R}$ software (version in 3.4.1).

\section{Result}

\section{Characteristics of study subjects}

The characteristics of 8693 participants (4113 women and 4580 men) from the 2009 wave of CHNS were shown in Table 1. Participants were categorized into quartiles of energy-adjusted total protein intake. Only actual daily dietary intake without energy adjustment were presented in the daily nutrient intakes of Table 1, but energyadjusted nutrients intakes were applied in the following statistical analysis.

Over the quartiles of energy-adjusted total protein intake, mean dietary intakes of all kinds of animal protein (total animal protein and the protein from red meat, poultry, seafood, dairy and egg), plant protein from nuts and seeds, legumes and cholesterol increased, whereas mean dietary intake of protein from coarse cereals decreased. Participants who consumed more daily protein had high education level, annual income, tea and coffee consumption, proportion of urban residents, BMI and lower level of physical activity.

\section{Dietary protein food patterns and the association with T2DM}

Subjects were categorized into three different dietary protein food patterns, whose name were determined by the highest percentage of intake from one or two food groups. Percentage protein contribution from each specific food group was shown in Table 2. Compared to other groups, the "legumes and seafood" dietary pattern (mean percentage protein contribution from legumes and seafood: 14.3 and $8.7, \mathrm{n}=2984$ ) presented with a relatively higher protein intake from legumes, seafood, nuts and seeds, coarse cereals, fruits, poultry, dairy, and eggs. The "Red meat" and "refined grains" dietary patterns presented with higher protein consumption from red meat $(33.1 \%)$ and refined grains $(63.5 \%)$ respectively.

In multivariate-adjusted models, when compared to the T2DM prevalence of the "legumes and seafood" dietary pattern, ORs $(95 \% \mathrm{CI})$ for T2DM were 1.49 (1.15, $1.97)$ and $1.45(1.12,1.91)$ in the "red meat" and "refined grains" respectively (Table 3 ).

\section{Subgroup analysis of the association between protein intake and T2DM by dietary protein food patterns}

After adjustment for covariates, the OR for T2DM over extreme quartiles (highest vs. lowest) of energy-adjusted total protein intake was 3.12 [95\% CI 1.65-5.91; $P$ for trend $<0.001]$ in the "red meat" group (Table 4), and there is no significant association between total protein intake and T2DM in the total population [OR: $1.23(0.89$, 1.69)].

In the total population, animal protein intake demonstrated a non-significant positive relation with T2DM [OR: $1.32(0.93,1.89)]$. In the subgroup analyses, there was a positive association between animal protein intake and T2DM in the "red meat" group [OR: 3.48 (1.87, 6.60)]. However, the association between animal protein intake and T2DM was significantly inversed in the "refined grains" group [OR: $0.55(0.32,0.89)]$.

Overall, plant protein intake was significantly inversed related to T2DM after adjustment for all covariates [OR: $0.72(0.51,0.95)]$. Moreover, plant protein intake was negatively related to T2DM [OR: $0.58(0.33,0.96)]$ in the "legumes and seafood" subgroup. This association was not significant in the "red meat" and "refined grains" dietary patterns. Sensitivity analyses excluding subjects with previously diagnosed type 2 diabetes was repeated in the statistical analysis and similar results were obtained (data not shown). Additional analyses were also conducted to assess the associations of quartiles of energy-adjusted protein intake from different animal or plant sources with T2DM. Protein intake from red meat [OR: 2.34 $(1.35,4.12)]$, or refined grains [OR: $2.15(1.37,3.41)]$ was positively related with T2DM risks. In contrast, protein intake from legumes [OR: $0.57(0.32,0.95)]$, or vegetables [OR: $0.66(0.37,0.94)]$ was negatively related with T2DM risks. There was no significant association between protein intake from poultry, dairy, eggs, seafood, coarse cereals, tubers, nuts and seeds, or fruits (data not shown).

\section{Discussion}

In this study, higher intake of vegetable protein was negatively associated with T2DM risk in Chinese population. Furthermore, after categorizing subjects into different dietary protein food patterns, the inverse association between plant protein intake and T2DM risk remained in the "legumes and seafood" dietary pattern. The positive relation between total protein and animal protein with T2DM risk were significant and independent in the "red meat" dietary pattern, whereas in the "refined grains" dietary patterns, animal protein intake was associated with a lower T2DM risk. These finding suggested that considering protein intake from a whole-diet perspective of dietary pattern is necessary for T2DM prevention.

Our findings of positive association between total and animal protein intake with T2DM risk in the "red meat" dietary pattern was consistent with previous studies reported in northeastern Chinese, American, and European populations $[5,6,8,24]$. The quantity and composition of protein intake in the "red meat" dietary pattern was similar with these studies. Participants have 
Table 1 Characteristics and dietary consumption in a cross-sectional study by categories of energy-adjusted total protein intake

Q1:50.8 g/day $(46.3,53.6)^{\mathrm{a}} \quad$ Q2:59.6 g/day $(57.8,61.5)^{\mathrm{a}} \quad$ Q3:68.0 g/day $(65.7,70.4)^{\mathrm{a}} \quad$ Q4:81.6 g/day $(76.3,89.9)^{\mathrm{a}}$

Demographic and lifestyle factors

\begin{tabular}{|c|c|c|c|c|}
\hline N (cases) & $2173(146)$ & $21,734(128)$ & $2173(145)$ & $2174(142)$ \\
\hline $\mathrm{BMI}\left(\mathrm{kg} / \mathrm{m}^{2}\right)$ & $23.0 \pm 3.5$ & $23.2 \pm 3.5$ & $23.4 \pm 3.4$ & $23.6 \pm 3.5$ \\
\hline $\operatorname{PAL}(\times B M R)$ & $1.70 \pm 0.32$ & $1.65 \pm 0.30$ & $1.62 \pm 0.29$ & $1.60 \pm 0.29$ \\
\hline \multicolumn{5}{|l|}{ Residence area } \\
\hline Urban (\%) & 19.8 & 26.2 & 36.5 & 44.4 \\
\hline \multicolumn{5}{|l|}{ Gender } \\
\hline Male (\%) & 49.1 & 43.4 & 46.0 & 50.6 \\
\hline \multicolumn{5}{|l|}{ Education level } \\
\hline Low (\%) & 52.7 & 46.0 & 39.9 & 32.3 \\
\hline Middle (\%) & 44.3 & 50.1 & 53.6 & 60.1 \\
\hline High (\%) & 3.0 & 3.9 & 6.4 & 7.6 \\
\hline \multicolumn{5}{|l|}{ Annual income, RMB } \\
\hline$<9000$ & 68.5 & 65.2 & 53.6 & 50.7 \\
\hline $9000-15,000$ & 16.4 & 18.9 & 22.3 & 21.9 \\
\hline$>15,000-25,000$ & 10.4 & 10.7 & 14.9 & 16.9 \\
\hline$>25,000$ & 4.7 & 5.2 & 9.2 & 10.5 \\
\hline Former or current smoking (\%) & 33.4 & 30.2 & 28.0 & 33.1 \\
\hline Tea consumption (yes, \%) & 29.0 & 29.6 & 31.7 & 36.4 \\
\hline Coffee consumption (yes, \%) & 1.3 & 1.7 & 2.4 & 4.0 \\
\hline Alcohol consumption (yes, \%) & 20.9 & 17.3 & 20.7 & 22.2 \\
\hline \multicolumn{5}{|l|}{ Daily nutrient intakes } \\
\hline Total energy $(\mathrm{kcal} / \text { day })^{\mathrm{b}}$ & $2277.1 \pm 658.0$ & $1976.1 \pm 582.4$ & $2031.8 \pm 595.7$ & $2234.5 \pm 618.6$ \\
\hline Total protein (g/day) $)^{\mathrm{b}}$ & $52.4 \pm 15.7$ & $55.5 \pm 15.5$ & $65.4 \pm 16.0$ & $87.9 \pm 22.6$ \\
\hline Total protein (energy\%) ${ }^{b}$ & $9.2 \pm 1.1$ & $11.3 \pm 0.6$ & $13.1 \pm 1.0$ & $16.0 \pm 2.4$ \\
\hline Animal protein $(\mathrm{g} / \text { day })^{\mathrm{b}}$ & $10.6 \pm 8.8$ & $12.8 \pm 8.9$ & $17.7 \pm 10.4$ & $29.0 \pm 16.4$ \\
\hline From red meat $(\mathrm{g} / \text { day })^{\mathrm{b}}$ & $7.2 \pm 7.5$ & $8.3 \pm 7.7$ & $10.5 \pm 9.3$ & $18.0 \pm 14.5$ \\
\hline From poultry (g/day) ${ }^{b}$ & $0.8 \pm 2.3$ & $1.0 \pm 2.7$ & $2.1 \pm 4.4$ & $4.3 \pm 7.0$ \\
\hline From dairy $(g / \text { day })^{b}$ & $0.1 \pm 0.8$ & $0.2 \pm 1.0$ & $0.5 \pm 2.1$ & $0.8 \pm 2.8$ \\
\hline From egg (g/day) $)^{b}$ & $2.2 \pm 2.9$ & $3.0 \pm 3.5$ & $3.9 \pm 4.0$ & $5.0 \pm 5.6$ \\
\hline From seafood $(\mathrm{g} / \text { day })^{b}$ & $1.4 \pm 2.9$ & $2.0 \pm 3.9$ & $3.5 \pm 5.3$ & $7.3 \pm 9.7$ \\
\hline Plant protein (g/day) $)^{b}$ & $37.8 \pm 13.5$ & $37.7 \pm 13.9$ & $40.3 \pm 16.1$ & $47.1 \pm 21.7$ \\
\hline From grain $(\mathrm{g} / \text { day) })^{\mathrm{b}}$ & $28.7 \pm 11.4$ & $28.0 \pm 11.9$ & $28.5 \pm 13.7$ & $27.0 \pm 13.9$ \\
\hline From coarse cereals $(\mathrm{g} / \text { day })^{\mathrm{b}}$ & $2.0 \pm 3.8$ & $1.7 \pm 2.7$ & $1.5 \pm 2.8$ & $1.3 \pm 2.5$ \\
\hline From vegetable $(\mathrm{g} / \text { day })^{\mathrm{b}}$ & $4.6 \pm 3.0$ & $4.5 \pm 3.1$ & $4.7 \pm 3.3$ & $5.5 \pm 3.8$ \\
\hline From fruit (g/day) ${ }^{b}$ & $0.2 \pm 0.5$ & $0.2 \pm 0.5$ & $0.2 \pm 0.5$ & $0.3 \pm 0.6$ \\
\hline From legumes $(\mathrm{g} / \text { day })^{\mathrm{b}}$ & $2.3 \pm 3.8$ & $3.2 \pm 4.8$ & $5.2 \pm 6.5$ & $11.3 \pm 14.3$ \\
\hline From nuts and seeds $(\mathrm{g} / \text { day) })^{\mathrm{b}}$ & $0.3 \pm 1.7$ & $0.5 \pm 2.0$ & $0.7 \pm 3.0$ & $1.0 \pm 3.5$ \\
\hline From tubers $(g / \text { day })^{b}$ & $0.4 \pm 0.4$ & $0.4 \pm 0.4$ & $0.7 \pm 0.6$ & $1.9 \pm 0.7$ \\
\hline Total fat $(\mathrm{g} / \text { day })^{\mathrm{b}}$ & $86.3 \pm 42.7$ & $66.6 \pm 30.8$ & $67.5 \pm 30.1$ & $78.0 \pm 31.9$ \\
\hline Total fat (energy\%) ${ }^{b}$ & $33.7 \pm 11.6$ & $30.1 \pm 9.8$ & $29.9 \pm 9.6$ & $31.4 \pm 9.2$ \\
\hline Saturated fat (g/day) ${ }^{\mathrm{b}}$ & $10.7 \pm 9.0$ & $7.2 \pm 5.4$ & $7.2 \pm 5.2$ & $8.5 \pm 5.6$ \\
\hline Monounsaturated fat $(\mathrm{g} / \text { day })^{\mathrm{b}}$ & $21.2 \pm 15.5$ & $14.3 \pm 10.6$ & $14.0 \pm 10.0$ & $16.2 \pm 11.1$ \\
\hline Polyunsaturated fat $(g / \text { day })^{b}$ & $19.4 \pm 17.2$ & $13.7 \pm 10.0$ & $13.3 \pm 9.5$ & $14.2 \pm 9.6$ \\
\hline Total carbohydrate $(\mathrm{g} / \text { day })^{\mathrm{b}}$ & $324.5 \pm 105.9$ & $296.1 \pm 98.6$ & $299.2 \pm 105.7$ & $305.4 \pm 106.0$ \\
\hline Total carbohydrate (energy\%) & $57.7 \pm 11.7$ & $60.2 \pm 10.3$ & $58.8 \pm 10.2$ & $54.5 \pm 10.0$ \\
\hline Cholesterol (mg/day $)^{\mathrm{b}}$ & $171.1 \pm 154.7$ & $206.8 \pm 166.9$ & $269.3 \pm 175.4$ & $395.1 \pm 270.4$ \\
\hline Fiber $(g / d a y)^{b}$ & $10.5 \pm 5.8$ & $10.1 \pm 5.0$ & $11.6 \pm 7.2$ & $13.9 \pm 8.9$ \\
\hline
\end{tabular}

Values were presented as mean \pm standard deviation, median (IQRs) or proportions

a Estimated intake energy adjusted by the residual method

b Actual daily nutrients intake without energy adjustment 
Table 2 Average percentage of total protein intake from individual food group across protein food cluster analysis of $\mathbf{8 7 7 4}$ men and women from the CHNS study

\begin{tabular}{llll}
\hline Food group & $\begin{array}{l}\text { Legumes } \\
\text { and seafood }\end{array}$ & Red meat & Refined grains \\
\hline $\mathrm{N}$ (case) & $2984(182)$ & $2569(174)$ & $3140(204)$ \\
Red meat, \% & $10.9 \pm 7.1$ & $33.1 \pm 9.9$ & $7.3 \pm 7.6$ \\
Poultry, \% & $4.1 \pm 7.5$ & $3.3 \pm 6.0$ & $1.3 \pm 4.2$ \\
Dairy, \% & $1.0 \pm 3.9$ & $0.6 \pm 2.3$ & $0.1 \pm 1.2$ \\
Egg, \% & $6.7 \pm 6.6$ & $4.3 \pm 5.2$ & $5.3 \pm 6.2$ \\
Seafood, \% & $8.7 \pm 10.1$ & $4.7 \pm 6.6$ & $1.8 \pm 4.4$ \\
Refined grains, \% & $34.2 \pm 10.2$ & $33.9 \pm 10.2$ & $63.5 \pm 11.0$ \\
Coarse cereals, \% & $5.4 \pm 9.2$ & $1.9 \pm 4.0$ & $4.1 \pm 6.0$ \\
Vegetables, \% & $7.8 \pm 5.0$ & $8.0 \pm 4.6$ & $8.3 \pm 5.1$ \\
Fruits, \% & $0.5 \pm 1.1$ & $0.4 \pm 0.9$ & $0.2 \pm 0.7$ \\
Legumes, \% & $14.3 \pm 13.6$ & $4.8 \pm 6.1$ & $3.9 \pm 5.8$ \\
Tubers, \% & $0.2 \pm 1.0$ & $0.2 \pm 0.8$ & $0.1 \pm 0.4$ \\
Nuts and seeds, \% & $1.3 \pm 4.2$ & $0.7 \pm 2.5$ & $0.5 \pm 2.6$ \\
\hline Ak-means cluster andysiswas used to cassify paticipants &
\end{tabular}

A K-means cluster analysis was used to classify participants into mutually exclusive groups

Naming of clusters was determined by the value which represent the highest consumption of one or two food groups compared with other clusters

Percentage of total protein intake across the each food group was used Mean \pm SE

consumed a relatively high protein intake (even more than $50 \%$ of protein intake from animal protein). As for plant protein intake, our finding demonstrating a modest inverse association between plant protein intake and T2DM, was consistent with the pooled analysis of NHS, NHS II, and HPFS, which reported that whole grains, nuts, peanut butter, and beans were the main sources of plant protein intake [8]. However, most previous individual studies $[5,6,8,24]$ showed no significant association of plant protein intake with T2DM risks. The divergence might occur that plant protein were from different sources across different study populations.

Actually, dietary protein food patterns that last for a long period for a person and hardly change totally, can reflect the divergent sources of plant protein and animal protein $[20,21]$. Besides, nowadays dietary guidelines also focus on dietary patterns [25]. Therefore, the question was raised as to whether different relation may be occurred between protein intake with T2DM in various dietary protein food patterns.

Initially, we observed three typical dietary protein food patterns in the 2009 wave of CHNS. People with "legumes and seafood" dietary pattern consumed nearly $30 \%$ percentage of animal protein, and only $1 / 3$ of the animal protein was from read meat. This protein food pattern represents the traditional Chinese diet, which grains eaters foremost with high consumption of legumes and vegetables, and moderate use of animal food. It presented the lowest T2DM prevalence, lining with previous observations [26-28] that the dietary patterns rich in legumes, fruits and vegetables had a favorable effect on the prevention of T2DM. On the other hand, the "refined grains" dietary pattern had nearly $65 \%$ percentage of protein from refined grains. It was another typical Chinese diet, which consists of a variety of cereal products and tubers, contributing as the primary source of nutrients intake. Previous studies demonstrated this kind of dietary pattern was positively associated with diabetes [14, 28-30]. Not only high intake of refined grains is the pivotal individual risk factors related to Chinese diabetes burden, high intake of red meat also contributes Chinese diabetes burden $[29,31]$.

Furthermore, our results showed that the relation of protein intake to T2DM varied by dietary protein food patterns. The underlying molecular mechanism of divergent associations between protein intake and T2DM remain unclear, but potentially was related to the other components of the high intake of various protein-rich food sources. Additionally, this discrepancy also could not be ignored because of the differences in amino acid and protein composition. Not all protein sources modulate insulin secretion and insulin sensitivity with equal abilities in healthy and T2DM populations. Because certain dietary proteins, peptides and amino acids can directly affect insulin secretion and insulin sensitivity. For example, some amino acids are believed to interfere with insulin's ability to increase peripheral glucose uptake in skeletal muscle, or intervene with glucose metabolism

Table 3 The odds ratios of type 2 diabetes across three dietary patterns

\begin{tabular}{llllll}
\hline Dietary pattern & $\mathbf{H R}(\%)$ & $\mathbf{O R}_{\mathbf{1}}$ & $\mathbf{O R}_{\mathbf{2}}$ & $\mathbf{O R}_{\mathbf{3}}$ & $\mathbf{O R}_{\mathbf{4}}$ \\
\hline Legumes and seafood & 6.1 & 1 & 1 & 1 & 1 \\
Red meat & 6.8 & $1.33(1.05,1.66)$ & $1.38(1.09,1.75)$ & $1.43(1.11,1.85)$ & $1.49(1.15,1.97)$ \\
Refined grains & 6.5 & $1.23(0.99,1.55)$ & $1.39(1.10,1.78)$ & $1.40(1.11,1.80)$ & $1.45(1.12,1.91)$
\end{tabular}

Model 1: adjusted age (continuous), sex (male, female); Model 2: Model 1+PAL (continuous), smoking status (yes, no), alcohol consumption (yes, no), coffee consumption (yes, no), tea consumption (yes, no), annual income $(<9000 ; 9000-15,000 ;>15,000-25,000 ;>25,000)$ and education (low, middle, high); Model 3: Model $2+$ total energy intake (continuous), carbohydrate to energy ratio from refined grains or tubers, from the other plant sources (continuous), energy-adjusted intake (continuous) of total protein, SFA, PUFA, MUFA, fiber, and cholesterol; Model 4: Model $3+$ BMI (continuous) 
Table 4 The odds ratios of type 2 diabetes across quartiles of energy-adjusted total protein intake by dietary patterns

\begin{tabular}{|c|c|c|c|c|c|}
\hline & \multicolumn{4}{|c|}{ Energy-adjusted total protein intake quintiles, OR $(95 \% \mathrm{Cl})$} & \multirow[t]{2}{*}{ P for trend } \\
\hline & Q1 & Q2 & Q3 & Q4 & \\
\hline \multicolumn{6}{|l|}{ Total protein } \\
\hline Overall & 1 & $0.89(0.66,1.20)$ & $1.09(0.80,1.46)$ & $1.23(0.89,1.69)$ & 0.117 \\
\hline Legumes and seafood & 1 & $0.65(0.37,1.10)$ & $0.97(0.58,1.61)$ & $0.78(0.45,1.36)$ & 0.892 \\
\hline Red meat & 1 & $1.74(0.97,3.27)$ & $2.80(1.57,5.01)$ & $3.12(1.65,5.91)$ & $<0.001$ \\
\hline Refined grains & 1 & $0.93(0.58,1.51)$ & $1.02(0.62,1.69)$ & $1.06(0.63,1.81)$ & 0.298 \\
\hline \multicolumn{6}{|l|}{ Animal protein } \\
\hline Overall & 1 & $0.76(0.56,1.02)$ & $0.81(0.59,1.12)$ & $1.32(0.93,1.89)$ & 0.104 \\
\hline Legumes and seafood & 1 & $0.80(0.47,1.37)$ & $0.85(0.50,1.51)$ & $1.03(0.54,1.77)$ & 0.770 \\
\hline Red meat & 1 & $2.42(1.38,4.33)$ & $2.87(1.57,5.34)$ & $3.48(1.87,6.60)$ & $<0.001$ \\
\hline Refined grains & 1 & $0.70(0.45,1.10)$ & $0.64(0.40,1.03)$ & $0.55(0.32,0.89)$ & $<0.05$ \\
\hline \multicolumn{6}{|l|}{ Plant protein } \\
\hline Overall & 1 & $0.86(0.65,1.14)$ & $0.75(0.57,1.02)$ & $0.72(0.51,0.95)$ & $<0.05$ \\
\hline Legumes and seafood & 1 & $0.77(0.48,1.24)$ & $0.64(0.40,1.01)$ & $0.58(0.33,0.96)$ & $<0.05$ \\
\hline Red meat & 1 & $1.48(0.87,2.63)$ & $1.28(0.74,2.27)$ & $1.20(0.628,2.21)$ & 0.205 \\
\hline Refined grains & 1 & $0.88(0.54,1.42)$ & $1.06(0.67,1.69)$ & $1.09(0.67,1.81)$ & 0.289 \\
\hline
\end{tabular}

a Adjusted age (continuous), gender (male, female), PAL (continuous), smoking status (yes, no), alcohol consumption (yes, no), coffee consumption (yes, no), tea consumption (yes, no), annual income $(<9000 ; 9000-15,000 ;>15,000-25,000 ;>25,000)$, education (low, middle, high), total energy intake (continuous), carbohydrate to energy ratio from refined grains or tubers, from the other plant sources (continuous), energy-adjusted intake (continuous) of SFA, PUFA, MUFA, fiber, and cholesterol, BMI (continuous)

via stimulation of insulin and glucagon secretion and by serving as substrates for gluconeogenesis. Furthermore, certain dietary proteins, peptides and amino acids can indirectly influence the intermediate substance of insulin secretion such as glucose-dependent insulin tropic peptide (GIP) and glucagon-like peptide-1 (GLP-1) secretion $[32,33]$.

For the "legumes and seafood" dietary pattern, higher intake of plant protein reduced T2DM risks, which may be in part due to that increased protein intake was accompanied with more consumption of legumes, nuts and seeds, whole grains, vegetables, and fruits. These foods were proven to be beneficial for preventing T2DM due to high content of fiber, magnesium and vitamin [25, 34]. However, the association still existed after adjustment for these nutrient intakes. Thus, we may be able to propose a possibility that protein per se of these food items potentially benefited to decrease T2DM risk. The result was consistent with previous study that replacing meat protein with soy protein altered insulin resistance and blood lipids [35]. The mechanisms underlying the beneficial effect of soy protein might be explained for inhibiting lipogenesis or insulin secretion from pancreatic $\beta$ cells, which were believed to enhance lipolysis in the adipose and liver to reduce adiposity [36]. Additionally, a clinical trials found that changing dietary protein sources to plant and fish-based sources lowered the plasma branched chain amino acids (BCAAs) concentrations, which have been shown to be positively linked to diabetes risk [37]. Furthermore, insulin-like plant proteins may partly attribute to the relation. In several vitro and in vivo studies, insulin-like plant proteins was isolated from leave, seeds and fruits, which was proven to increase tolerance to orally administered glucose with hypoglycemic activity in chemically induced diabetic mice [38-40].

Contrary to the negative association between plant protein and T2DM in the "legumes and seafood" dietary pattern, the "refined grains" pattern leads an insignificant association. This may due to the different proteinrich food sources. Satija's study showed that not all plant foods are necessarily beneficial and found varied incidence of T2DM in different plant-based dietary patterns [25]. However, animal protein presented a protective effect in the "refined grains" dietary pattern, in which animal protein was less than $20 \%$ and mainly contributed from dairy, seafood, poultry and eggs. A high quality of the protein cluster, which was consisted of an optimal composition, may partly explain the benefit of relatively high animal protein. In most cases, the concentrations of crude protein and amino acid in the cereal grains, especially several cereal grains most available for human consumption, are not sufficient to fulfil crude protein and amino acid requirements for proper growth and development [41]. Wu et al. [42] proposed that an optimal composition of dietary amino acids could result in decreased risks of obesity and T2DM by enhancing the efficiency of amino acid metabolism. Findings from a prospective 
population-Based Study also reported that an unbalanced amino acid patterns might lead to dysglycemia risk. Thus, appropriate amount animal protein from these food items was recommended to the "refined grains" patterns.

However, higher animal intake increased T2DM risks in the "red meat" dietary pattern. As the main animal protein sources, red meat was reported to increase T2DM risks independent of fat intake [43, 44]. Heme iron, nitrites and advanced glycation end products are thought to mediate the association [7]. In our study, after adjusting estimated iron intake and processed meat intake, the association was attenuated but remained significant. This result was similar with the results of Nurses' Health Study [8], which suggested that the direct effect of protein from meat cannot be excluded. This association may mainly be due to amino acid composition. Floegel et al. [45] found BCAAs performed a high circulation level after red meat intake. Compared with a meal mainly from vegetable sources, a meal mainly from red meat sources leads an even nearly $100 \%$ higher plasma concentrations of BCAAs [46]. Furthermore, Wu et al. found that BCAA contributes to develop insulin resistance in a poor dietary pattern including high fat consumption. The results of Metabolite-profiling studies also reported five branchedchain and aromatic (isoleucine, leucine, valine, tyrosine and phenylalanine) were highly associated with diabetes [47]. It suggested BCAAs activated mammalian target of rapamycin complex 1 (mTORC1), so that caused insulin resistance [48] although relation of amino acid to T2DM risk need to be further elucidated.

Limitations of this study were as follows. Firstly, we cannot establish causal relationship as our study was cross-sectional. However, we have run sensitivity analyses excluding subjects with previously diagnosed type 2 diabetes and found similar results, demonstrating that the possibility of reverse causation which subjects changed their diet following diagnosis was less likely to happen. Large-scale longitudinal study and longterm study are warranted. Secondly, the 3 consecutive 24-h recalls randomly allocated in a week may not reflect the long-term protein intake. However, it was suggested that duplicate 24-h recalls could be used to asses intakes of nutrients, such as protein, carbohydrates, starch, sugar, water, potassium and calcium [49], and the 3 consecutive days were used in many population studies $[50,51]$. In this study, we also adjusted the condiments intake according to a food inventory of household. Thirdly, potential residual confounding may exist although we adjusted a number of potential confounders in analyses. Fourthly, there were the disadvantages to cluster analysis including sensitivity to outliers and subjective interpretation of the clusters after the complete statistical model. Thus, we employed the details described in methods to remove the outliers and set standards for outlined decisions of the cluster.

\section{Conclusions}

The results of our study suggested the associations between protein intake and T2DM vary by dietary pattern. Dose of protein intake may interact with dietary patterns. Our study suggested that dietary pattern may be considered into the recommendation of protein intake for diabetes prevention.

\section{Abbreviations}

T2DM: type 2 diabetes mellitus; OR: odds ratios; $95 \%$ Cl: $95 \%$ confidence interval; CHNS: China Health and Nutrition Survey; HbA1c: hemoglobin A1C; PAL: physical activities level; BMR: basal metabolism rate; BMI: body mass index; GIP: insulinotropic peptide; GLP-1: glucagon-like peptide-1; BCAAs: branched chain amino acids; mTORC1: mammalian target of rapamycin complex 1.

\section{Authors' contributions}

QK, LC, CC and MX imagined and designed the research; QK, LC, FH, YY and XB performed the statistical analyses; QK wrote the paper and edited the manuscript; MX, LC and CC reviewed manuscript; and MX had primary responsibility for the final content. All authors read and approved the final manuscript.

\section{Author details}

1 Department of Nutrition, School of Public Health, Sun Yat-sen University (Northern Campus), Guangzhou 510080, Guangdong Province, People's Republic of China. ${ }^{2}$ Department of Clinical Nutrition and Endocrinology, Sun Yat-sen Memorial Hospital, Sun Yat-sen University, 107 Yanjiang West Road, Guangzhou 510120, Guangdong Province, People's Republic of China. ${ }^{3}$ Department of Maternal and Child Health, School of Public Health, Sun Yatsen University (Northern Campus), Guangzhou 510080, Guangdong Province, People's Republic of China.

\section{Acknowledgements}

This research uses data from the China Health and Nutrition Survey (CHNS). We thank the National Institute for Nutrition and Health, China Center for Disease Control and Prevention, Carolina Population Center, the University of North Carolina at Chapel Hill for continuously financial support for the CHNS data collection and analysis files.

\section{Competing interests}

The authors declare that they have no competing interests.

\section{Availability of data and materials}

The datasets generated during the current study are available in the China Health and Nutrition Survey (CHNS) repository, http://www.cpc.unc.edu/proje cts/china/data.

\section{Consent for publication}

Not applicable.

\section{Ethics approval and consent to participate}

All the participants gave written informed consent. Protocol and analysis of the survey were approved by Chinese Center for Disease Control and Prevention, the China-Japan Friendship Hospital, the National Institute for Nutrition and Health, and the University of North Carolina at Chapel Hill.

\section{Funding}

This work was funded by the National Natural Science Foundation of China (31741105) and by the National Key Research and Development Program of China (No. 2016YFD0400602). 


\section{Publisher's Note}

Springer Nature remains neutral with regard to jurisdictional claims in published maps and institutional affiliations.

Received: 13 March 2018 Accepted: 4 June 2018

Published online: 15 June 2018

\section{References}

1. Ma RC, Lin X, Jia W. Causes of type 2 diabetes in China. Lancet Diabetes Endocrinol. 2014;2:980-91.

2. Chan JCN, Zhang Y, Ning G. Diabetes in China: a societal solution for a personal challenge. Lancet Diabetes Endocrinol. 2014;2:969-79.

3. Tremblay F, Lavigne C, Jacques $H$, Marette A. Role of dietary proteins and amino acids in the pathogenesis of insulin resistance. Annu Rev Nutr. 2007;27:293-310.

4. Promintzer M, Krebs M. Effects of dietary protein on glucose homeostasis. Curr Opin Clin Nutr Metab Care. 2006:9:463-8.

5. van Nielen M, Feskens EJ, Mensink M, Sluijs I, Molina E, Amiano P, Ardanaz

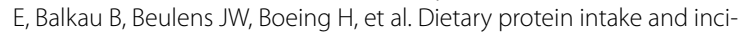
dence of type 2 diabetes in Europe: the EPIC-InterAct Case-Cohort Study. Diabetes Care. 2014;37:1854-62.

6. Sluijs I, Beulens JW, van der AD, Spijkerman AM, Grobbee DE, van der Schouw YT. Dietary intake of total, animal, and vegetable protein and risk of type 2 diabetes in the European Prospective Investigation into Cancer and Nutrition (EPIC)-NL study. Diabetes Care. 2010;33:43-8.

7. Pan A, Sun Q, Bernstein AM, Schulze MB, Manson JE, Willett WC, Hu FB. Red meat consumption and risk of type 2 diabetes: 3 cohorts of US adults and an updated meta-analysis. Am J Clin Nutr. 2011;94:1088-96.

8. Malik VS, Li Y, Tobias DK, Pan A, Hu FB. Dietary protein intake and risk of type 2 diabetes in US men and women. Am J Epidemiol. 2016;183:715-28

9. Pan A, Sun Q, Manson JE, Willett WC, Hu FB. Walnut consumption is associated with lower risk of type 2 diabetes in women. J Nutr. 2013;143:512-8.

10. Villegas R, Gao YT, Yang G, Li HL, Elasy TA, Zheng W, Shu XO. Legume and soy food intake and the incidence of type 2 diabetes in the Shanghai Women's Health Study. Am J Clin Nutr. 2008;87:162-7.

11. Popkin BM, Du S, Zhai F, Zhang B. Cohort Profile: the China Health and Nutrition Survey - monitoring and understanding socio-economic and health change in China, 1989-2011. Int J Epidemiol. 2010;39:1435-40.

12. Zhang B, Zhai FY, Du SF, Popkin BM. The China health and nutrition survey, 1989-2011. Obes Rev. 2014;15(Suppl 1):2-7.

13. Batis C, Mendez MA, Sotres-Alvarez D, Gordon-Larsen P, Popkin B. Dietary pattern trajectories during 15 years of follow-up and $\mathrm{HbA} 1 \mathrm{C}$, insulin resistance and diabetes prevalence among Chinese adults. J Epidemiol Community Health. 2014;68:773-9.

14. Yan S, Li J, Li S, Zhang B, Du S, Gordon-Larsen P, Adair L, Popkin B. The expanding burden of cardiometabolic risk in China: the China Health and Nutrition Survey. Obes Rev. 2012;13:810-21.

15. Yang Y, Wang G, Pan X. The 2002 Chinese food composition table. Beijing: Medical Publishing House of Beijing University; 2002.

16. Yang Y-X. Chinese food composition table 2004. Beijing: Peking University Medical Press; 2005.

17. Willett WC, Howe GR, Kushi LH. Adjustment for total energy intake in epidemiologic studies. Am J Clin Nutr. 1997;65:1220S-8S (discussion 1229S-1231S)

18. S-S Wang, Lay S, Yu H-N, Shen S-R. Dietary Guidelines for Chinese Residents (2016): comments and comparisons. J Zhejiang Univ Sci B. 2016;17:649-56.

19. Society CN. Chinese Dietary Reference Intakes. 1st ed. Beijing: China Light Industry Press; 2000 (in Chinese).

20. Mangano KM, Sahni S, Kiel DP, Tucker KL, Dufour AB, Hannan MT. Bone mineral density and protein-derived food clusters from the Framingham Offspring Study. J Acad Nutr Diet. 2015;115(1605-1613):e1601.

21. Mangano KM, Sahni S, Kiel DP, Tucker KL, Dufour AB, Hannan MT. Dietary protein is associated with musculoskeletal health independently of dietary pattern: the Framingham Third Generation Study. Am J Clin Nutr. 2017:105:714-22.
22. Quatromoni PA, Copenhafer DL, Demissie S, D'Agostino RB, O'Horo CE, $\mathrm{Nam} \mathrm{BH}$, Millen BE. The internal validity of a dietary pattern analysis. The Framingham Nutrition Studies. J Epidemiol Community Health. 2002;56:381-8.

23. Zhang CX, Ho SC, Fu JH, Cheng SZ, Chen YM, Lin FY. Dietary patterns and breast cancer risk among Chinese women. Cancer Causes Control. 2011;22:115-24.

24. Li J, Sun C, Liu S, Li Y. Dietary protein intake and type 2 diabetes among women and men in Northeast China. Sci Rep. 2016:6:37604.

25. Satija A, Bhupathiraju SN, Rimm EB, Spiegelman D, Chiuve SE, Borgi L, Willett WC, Manson JE, Sun Q, Hu FB. Plant-based dietary patterns and incidence of type 2 diabetes in US men and women: results from three prospective cohort studies. PLoS Med. 2016;13:e1002039.

26. Erber E, Hopping BN, Grandinetti A, Park SY, Kolonel LN, Maskarinec G. Dietary patterns and risk for diabetes: the multiethnic cohort. Diabetes Care. 2010;33:532-8.

27. Chanson-Rolle A, Meynier A, Aubin F, Lappi J, Poutanen K, Vinoy S, Braesco V. Systematic review and meta-analysis of human studies to support a quantitative recommendation for whole grain intake in relation to type 2 Diabetes. PLoS ONE. 2015;10:e0131377.

28. He Y, Ma G, Zhai F, Li Y, Hu Y, Feskens EJ, Yang X. Dietary patterns and glucose tolerance abnormalities in Chinese adults. Diabetes Care. 2009;32:1972-6.

29. Maghsoudi Z, Ghiasvand R, Salehi-Abargouei A. Empirically derived dietary patterns and incident type 2 diabetes mellitus: a systematic review and meta-analysis on prospective observational studies. Public Health Nutr. 2016:19:230-41.

30. Villegas R, Liu S, Gao YT, Yang G, Li H, Zheng W, Shu XO. Prospective study of dietary carbohydrates, glycemic index, glycemic load, and incidence of type 2 diabetes mellitus in middle-aged Chinese women. Arch Intern Med. 2007:167:2310-6.

31. Li Y, Wang DD, Ley SH, Vasanti M, Howard AG, He Y, Hu FB. Time trends of dietary and lifestyle factors and their potential impact on diabetes burden in China. Diabetes Care. 2017;40:1685-94.

32. Promintzer $M$, Krebs M. Effects of dietary protein on glucose homeostasis. Curr Opin Clin Nutr Metab Care. 2006;9:463.

33. Tremblay F, Lavigne $C$, Jacques $H$, Marette A. Role of dietary proteins and amino acids in the pathogenesis of insulin resistance. Annu Rev Nutr. 2007;27:293.

34. Villegas R, Gao Y, Yang G, Li H, Elasy T, Zheng W, Shu X. Legume and soy food intake and the incidence of type 2 diabetes in the Shanghai Women's Health Study. Am J Clin Nutr. 2008:87:162-7.

35. van Nielen M, Feskens EJ, Rietman A, Siebelink E, Mensink M. Partly replacing meat protein with soy protein alters insulin resistance and blood lipids in postmenopausal women with abdominal obesity. J Nutr. 2014;144:1423-9

36. Bhathena SJ, Velasquez MT. Beneficial role of dietary phytoestrogens in obesity and diabetes. Am J Clin Nutr. 2002;76:1191-201.

37. Elshorbagy A, Jerneren F, Basta M, Basta C, Turner C, Khaled M, Refsum $H$. Amino acid changes during transition to a vegan diet supplemented with fish in healthy humans. Eur J Nutr. 2017:56:1953-62.

38. Paula PC, Oliveira JTA, Sousa DOB, Alves BGT, Carvalho AFU, Franco $\mathrm{OL}$, Vasconcelos IM. Insulin-like plant proteins as potential innovative drugs to treat diabetes-The Moringa oleifera case study. N Biotechnol. 2017:39:99-109.

39. Joshi BN, Munot H, Hardikar M, Kulkarni AA. Orally active hypoglycemic protein from Costus igneus NE Br:: an in vitro and in vivo study. Biochem Biophys Res Commun. 2013;436:278-82.

40. Collier E, Watkinson A, Cleland CF, Roth J. Partial purification and characterization of an insulin-like material from spinach and Lemna gibba G3. Biol Chem. 1987;262:6238.

41. Cervantes-Pahm SK, Liu Y, Stein HH. Digestible indispensable amino acid score and digestible amino acids in eight cereal grains. Br J Nutr. 2014;111:1663-72.

42. Wu G. Amino acids: metabolism, functions, and nutrition. Amino Acids. 2009:37:1-17

43. Fung TT, Schulze M, Manson JE, Willett WC, Hu FB. Dietary patterns, meat intake, and the risk of type 2 diabetes in women. Arch Intern Med. 2004;164:2235-40. 
44. Schulze MB, Manson JE, Willett WC, Hu FB. Processed meat intake and incidence of type 2 diabetes in younger and middle-aged women. Diabetologia. 2003;46:1465-73.

45. Floegel A, Stefan N, Yu Z, Mühlenbruch K, Drogan D, Joost HG, Fritsche A, Häring HU, Angelis MHD, Peters A. Identification of serum metabolites associated with risk of type 2 diabetes using a targeted metabolomic approach. Diabetes. 2013;62:639.

46. Brandsch C, Shukla A, Hirche F, Stangl Gl, Eder K. Effect of proteins from beef, pork, and turkey meat on plasma and liver lipids of rats compared with casein and soy protein. Nutrition. 2006;22:1162-70.

47. Wang TJ, Larson MG, Vasan RS, Cheng S, Rhee EP, McCabe E, Lewis GD, Fox CS, Jacques PF, Fernandez C, et al. Metabolite profiles and the risk of developing diabetes. Nat Med. 2011;17:448-53.

48. Newgard CB, An J, Bain JR, Muehlbauer MJ, Stevens RD, Lien LF, Haqq AM, Shah SH, Arlotto M, Slentz CA, et al. A branched-chain amino acid-related metabolic signature that differentiates obese and lean humans and contributes to insulin resistance. Cell Metab. 2009;9:311-26.
49. Shamah-Levy T, Rodríguez-Ramírez S, Gaona-Pineda EB, Cuevas-Nasu L, Carriquiry AL, Rivera JA. Three 24-hour recalls in comparison with one improve the estimates of energy and nutrient intakes in an urban Mexican population. J Nutr. 2016;146:1043-50.

50. Willem DK, Inge H, Veerle DV, Stefanie V, Nadia S, Herman VO, Stefaan $\mathrm{DH}$. Repeated 24-hour recalls versus dietary records for estimating nutrient intakes in a national food consumption survey. Food Nutr Res. 2011;55:122-30.

51. Barquera S, Hernandez-Barrera L, Campos-Nonato I, Espinosa J, Flores M, Barriguete JA, Rivera JA. Energy and nutrient consumption in adults: analysis of the Mexican National Health and Nutrition Survey 2006. Salud Publica Mex. 2009;51(Suppl 4):S562-73.
Ready to submit your research? Choose BMC and benefit from:

- fast, convenient online submission

- thorough peer review by experienced researchers in your field

- rapid publication on acceptance

- support for research data, including large and complex data types

- gold Open Access which fosters wider collaboration and increased citations

- maximum visibility for your research: over $100 \mathrm{M}$ website views per year

At BMC, research is always in progress.

Learn more biomedcentral.com/submissions 